\title{
RICHNESS, DISTRIBUTION AND IMPORTANT AREAS TO PRESERVE BULBOPHYLLUM IN THE NEOTROPICS
}

\author{
Eric C. SmidT ${ }^{1,3}$, Viviane Silva-Pereira ${ }^{1}$, Eduardo L. Borba ${ }^{2}$ \\ \& CÁSSIO VAN DEN BERG ${ }^{1}$ \\ ${ }^{1}$ Universidade Estadual de Feira de Santana, Departamento de Ciências Biológicas, Laboratory of Plant Molecular \\ Systematics (LAMOL), BR 116, Km 03, Feira de Santana, Bahia, 44130-460, Brazil. \\ ${ }^{2}$ Universidade Federal de Minas Gerais, Instituto de Ciências Biológicas, Departamento de Botânica, \\ Av. Antônio Carlos, 6627, Pampulha, Belo Horizonte, Minas Gerais, 31270-110, Brazil. \\ ${ }^{3}$ Author for correspondence: ecsmidt@yahoo.com.br
}

Key Words: Bulbophyllum, Neotropics, richness, complementarity analysis, PAE, orchid

\section{Introduction}

Bulbophyllum is probably one of the largest genera in the orchids with Pantropical occurence, but the distribution is not homogeneous across the world. The Paleotropics is the richest area and there are hundreds of species in Asia (Vermeulen 1991). The genus was described by Thouars in 1822 , and the first Neotropical species was described only in 1838 (B. setigerum Lindl.) from a plant collected in Guayana by George Loddiges and sent to John Lindley. Until today, one hundred and ten species names were published for the Neotropics, however only $c a$. 70 species could be recognized in five sections supported by phylogenetic studies based on nuclear and chloroplast genome sequence data (Smidt unpubl. data).

Richness is a fundamental measurement of community and regional diversity, and underlays many ecological models and conservation strategies (Magurran 1988). Due to the vast area of the Neotropical region, we know that the sample effort is not consistent throughout the range. Some areas could be richer than others because they are near cities and others could be considered poor in number of species because they are rarely or never sampled. Keeping this in mind, we can use richness estimation to infer the richness from incomplete collections and projecting the probable number of species to be found. The literature about estimation of species richness is extensive (e.g. Colwell \& Coddington 1994, Walther \& Morand 1998, Hellmann \& Fowler 1999, Gotelli \& Colwell 2001), and have been used to evaluate global richness of different organisms (e.g. Jarvis et al. 2002, Meier \& Dikow 2004).
In this study, the richness patterns, relationships of the Neotropical biomes and complementarity analyses of the genus were accomplished by using a GIS framework, considering the proposed phytogeographical areas for the American Continent (Atlantic Rain Forest, Cerrado, Semi-arid, Andean region, Amazon, Highlands Guayana, Mesoamerica, Caribbean and Mexico).

\section{Methodology}

SAMPLE DATA - The specimen database was generated during the taxonomic review of Neotropical Bulbophyllum species and the information was obtained from ca. 1400 specimens deposited in 65 herbaria in Brazil, Europe and other American countries. All analyses of this study was undertaken using free DIVA-GIS software v. 5.4 (Hijmans et al. 2000, 2001) and Arcview GIS 3.3 (ESRI 1999) using the Americas Base Map for Flora Neotropica.

RiCHNESS - This study explored the species richness of Neotropical Bulbophyllum, by the number of taxa occurring in cells with $1^{\circ} \times 1^{\circ}$ size in a grid map. This approach permits us to evaluate where are and the range size of this areas to employ conservation decisions about this taxa. We applied five non-parametric species richness estimators (Chao 1, Chao 2, Jackknife 1, Jackknife 2 and ACE, see Colwell \& Coddington (1994) for explanation of these estimators), to know how many species of Bulbophyllum are probable to be discovered in the Neotropical region, and which biomes are potentially richer. Each estimator used here presents different assumptions and bias, 
but the overall difference between them is how it works with species collected one time (singletons) and two times (doubletons) in the analyses. Many studies with simulation or empiric data have showed that the behavior of these estimators is influenced by the data set, but are of great utility to compare the estimates between different groups in the same environment or compare different environment for the same taxa, e.g. Colwell \& Coddington (1994), Meier \& Dikow (2004).

COMPLEMENTARITY ANALYSIS - In order to determine optimal locations for in situ reserves to conserve maximum species diversity, a study based on species complementarity was carried out using the algorithm described by Rebelo (1994) and Rebelo \& Sigfried (1992). The aim was identify grid cells with defined size, which complement each other in terms of species composition. The process is iterative, whereby the first cell is the richest in number of species. The second iteration locates a grid cell that is richest in species not already represented in the first iteration. This iterative process continues until all species have been represented. We computed the minimum number of grid cells needed to capture all 71 Neotropical Bulbophyllum species.

PAE ANALYSIS - The parsimony analysis represents a direct tool for searching the most parsimonious arrangement of shared species among areas, aiming to reveal the biogeographical affinities in a hierarchical pattern (Rosen \& Smith 1988, Trejjo-Torres \& Ackerman 2001, Garcia-Barros et al. 2002). This approach was originally called parsimony analysis of endemicity (PAE), developed by Rosen \& Smith (1988), and employed in the study of orchids of Caribbean islands (Trejjo-Torres \& Ackerman 2001).

The units of comparison that have usually been applied are sites, quadrants or sections of regions, biogeographical areas, or natural geographical areas. In this work, we used well accepted phytogeographical areas, as those discussed by Gentry (1982) for the Neotropics. Among them, nine areas or Biomes (Atlantic Rain Forest, Cerrado, Semi-arid, Andean, Amazon and Guayana Highlands, Mesoamerica, Caribbean Islands and México) were considered.

A presence/absence matrix of the 71 Bulbophyllum species (including varieties) was constructed in
Nexus Editor Software (Page 2001), where presence was indicated with a ' 1 ' and absence with a ' 0 '. Using this program, areas were entered in the place of taxa, while taxa were entered in the place of characters. Once we constructed the matrix, the analyses of parsimony were done using PAUP 4.10 (Swofford 2000). A hypothetical outgroup area with all 0s (no species) was used in the analyses in order to root the trees. Exhaustive search was carried out to look for the most parsimonious trees, which indicate the floristic affinities among studied areas. We obtained a Majority Rule Consensus Trees for equally parsimonious trees founded and assessed the clade robustness using bootstrap proportions with 1000 replicates (Felsenstein 1985).

\section{Results and Discussion}

GENERAL Distribution - Although there are ca. 1400 specimens available from different herbaria, only ca. 900 could be geographically referenced based on specimen labels, due to the uncertainty or lack of the locality indications. Some species were plotted on map only from type specimens or protologue information because of absence of field sample.

The generic distribution of Bulbophyllum in the Neotropics is limited at the South by Rio Grande do Sul (Brazil) and Mexico at the North; at the East it is limited by Pernambuco, Brazil and West by Cordova, Mexico. The historical record of North limit of the genus in Everglades, Florida (Luer 1972) was not confirmed by herbarium specimens.

Richness - The "global" richness through the Neotropics is obviously different from richness of any political boundaries, and the richness of a particular country needs to be evaluated in another scale with smaller grids than those used in this work. According to our results, the highest number of Neotropical Bulbophyllum species can be found in Southeast Brazil $\left(22^{\circ} \mathrm{S}-42^{\circ} \mathrm{W}\right)$ more specifically in the contact areas between Cerrado and Atlantic Rainforest (fig. 1). Among the biomes or phytogeographical regions considered, the greatest richness were reported for South American Cerrado biome (35 spp) followed by Atlantic Rainforest (31 spp), and Andean region (17 spp) (tab. 1). Despite the low richness, three species are endemic to Mexico, while the 


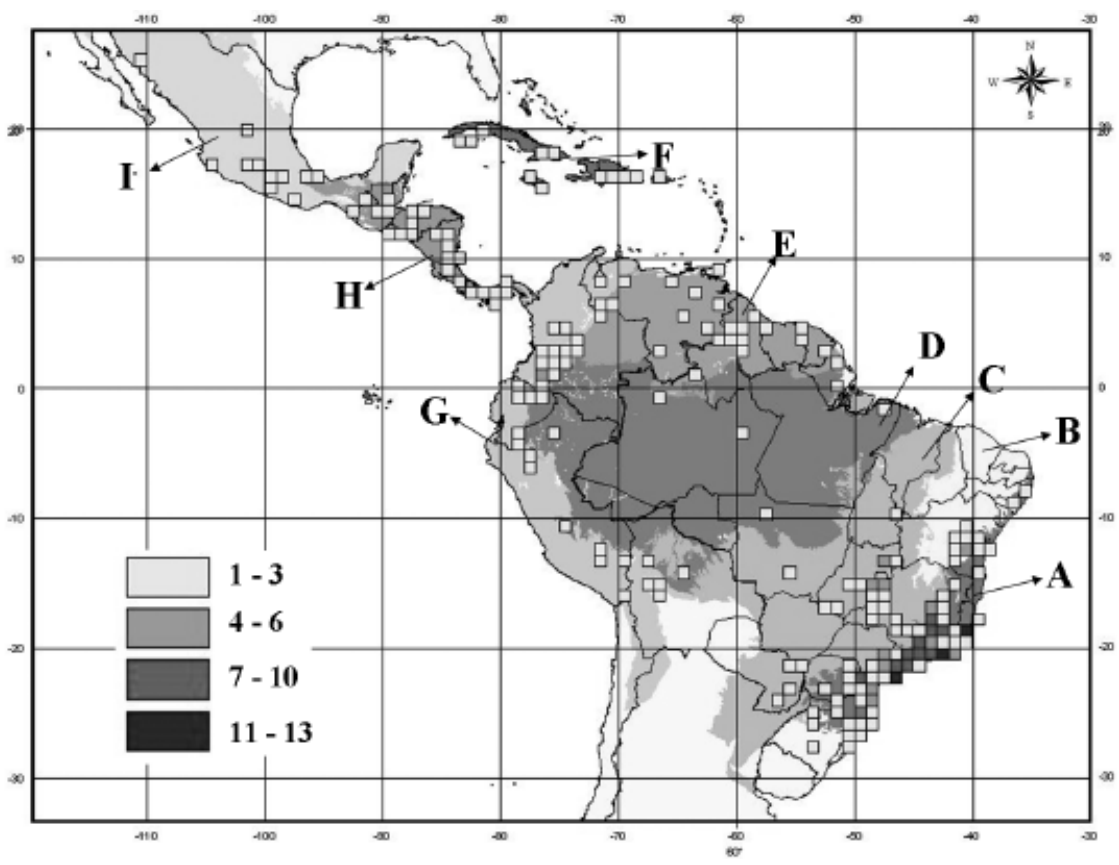

FiguRE 1. Species richness of Bulbophyllum data set plotted into grid cells of equal area (ca. $12,000 \mathrm{Km}^{2}$, the $1^{\circ} \times 1^{\circ}$ Flora Neotropica grid). Values are represented by the number of species present in each cell and the phytogeographical areas by the follow letters: A. Atlantic Rain Forest, B. Semi-arid, C. Cerrado, D. Amazon, E. Guayana Highlands, F. Caribbean Islands, G. Andean, H. Mesoamerica, I. Mexico.

Central America and Caribbean Islands did not present any endemic species.

Considering the estimation of global richness in the Neotropics, the indexes applied indicate that, until today, $50-90 \%$ of Bulbophyllum species were collected (tab. 1). Although different estimations have been obtained among the biomes, once the richness estimators seem to be sensible to poorly sampled areas and positive biased with highly collected areas, some regional richness patterns for different phytogeographical regions can be explained.

In general, according to the richness estimation analysis, the Cerrado and the Atlantic Forest have the largest number of species and also great amount of collections too, probably being the best sampled areas. In this context, the Andean region is supposed to be one of the richest areas rather than other sites with more samples and species collected. Although only 17 species have been registered, the quantitative estimators Chao 1 and Chao 2 indicate more than 40 species to be discovered in that region, probably due to the effect of few collections (and consequently more single and doubletons) for the estimations.
A pattern that emerges from the Bulbophyllum diversity seems to be the affinities of this genus with outcropping mountain habitats. The Brazilian southeast mountain area presents half of the collected species for the Neotropics, constituting the richest vegetation in species of Bulbophyllum for the American continent. The conglomerate of mountains considered in this work extends from Rio de Janeiro to Bahia State and do not present a unique geological origin, being usually divided in three blocks: 1 - the adjacent mountains of the National Park of Itatiaia on the south portion, 2- mountains adjacent to Serra do Cipó in the central area, in Minas Gerais State and 3Chapada Diamantina in Bahia State in the north. Each of these portions of mountains is in contact with different biomes, especially Cerrado and Atlantic Forest.

The low richness found in other ecosystems can be explained by different reasons. In the Amazon few collections have been carried out, except around Manaus - Belém area. In fact, lots of mountain formations in this phytogeographical area have never been explored for plant collection, being this place probably the most suitable to find Bulbophyllum species. 
TABLE 1. Species richness estimation for Bulbophyllum using five estimator indexes for different phytogeographical areas in the Neotropics.

\begin{tabular}{|c|c|c|c|c|c|c|c|}
\hline Estimator & Richness (S) & Observation & Chao-1 & Chao-2 & Jackknife-1 & Jackknife-2 & $\mathrm{ACE}$ \\
\hline Neotropics & 71 & 888 & 137 & 122 & 93 & 115 & 73 \\
\hline Cerrado & 34 & 316 & 41 & 39 & 42 & 51 & 35 \\
\hline Atlantic Rain Forest & 32 & 240 & 47 & 43 & 43 & 53 & 33 \\
\hline Mountains of Southeastern Brazilian & 30 & 302 & 40 & 37 & 39 & 47 & 32 \\
\hline Andes & 17 & 69 & 64 & 40 & 26 & 35 & 19 \\
\hline Semi-arid & 10 & 90 & 14 & 12 & 13 & 16 & 12 \\
\hline Guayana Highlands & 9 & 35 & 21 & 15 & 13 & 17 & 16 \\
\hline Mexico & 7 & 39 & 8 & 7 & 9 & 10 & 8 \\
\hline Amazon & 4 & 9 & 6 & 5 & 5 & 6 & 7 \\
\hline Caribbean Islands & 4 & 32 & 4 & 4 & 4 & 5 & 5 \\
\hline Mesoamerica & 2 & 50 & 2 & 2 & 2 & 2 & -1 \\
\hline
\end{tabular}

Other poor region for richness of this group is the Semi-arid, one of the less adequate biomes for Orchidaceae, due to low air humidity and rainfall. In accordance to the dataset the relative high observed and estimated richness in this biome is due to species sampled in interior mountain formations with humid forest growing around high altitude places.

A low richness was detected in Northern South America to Mesoamerica and in Caribbean islands, where mainly species of section Bulbophyllaria Rchb.f. (bifoliated plants with thickened inflorescence, known as "rat-tail orchid") are present. Finally, Mexico presents low richness but a relatively high number of endemic species growing especially in Oak forest and in high altitude places too.

PAE ANALYSIS - The parsimony analysis of endemicity, with the nine phytogeographical regions considered for the Neotropics using shared Bulbophyllum species, produced seven equally most parsimonious trees (fig. 2) with: tree length $=82$, Consistency index $(\mathrm{CI})=0.8537$, Retention index $(\mathrm{RI})=0.7600$. A strong floristic relationship was detected between: (1) Cerrado, Atlantic Rain Florest, Semi-arid and Andean biomes and (2) Amazon and Guayana Highlands, Mesoamerica, Caribbean and Mexico. The other Neotropical biomes do not have any Bulbophyllum species or are considered within the broader concepts used here to avoid small areas with few collections. Complementarity AnAlysis - According to our results thirty five main areas were identified using complementarity analysis and considered as prioritaire for the conservation of total diversity of Bulbophyllum in the Neotropics (Fig. 3).

The eight most important areas in the map encompass $54 \%$ of the 71 species considered in this study.

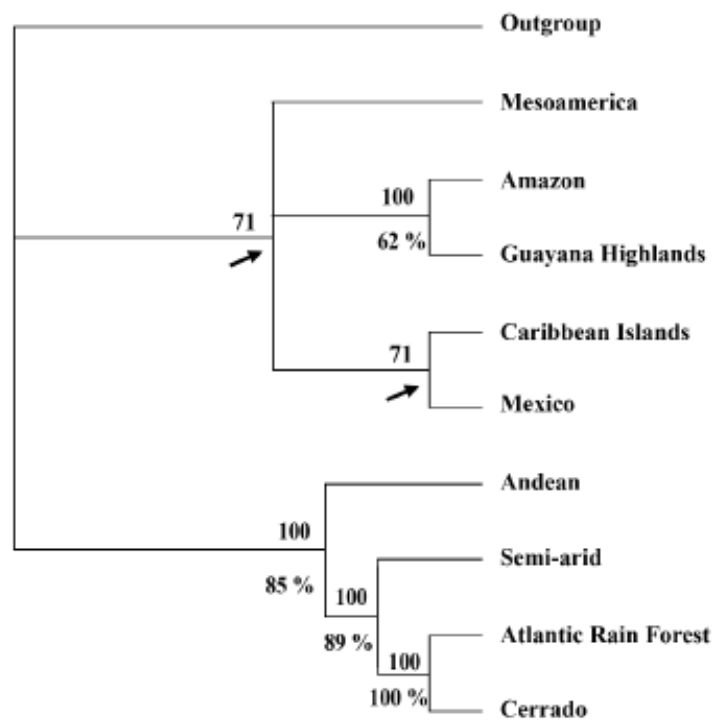

FIGURE 2. Relationship between Neotropical phytogeographical areas using Parsimony Analysis of Endemicity of Bulbophyllum species. The value above the branch is the Majority-Rule Consensus index of the seven most parsimonious trees and bootstrap support is below the branches. Nodes with less than $50 \%$ of bootstrap support are indicated with arrows. 


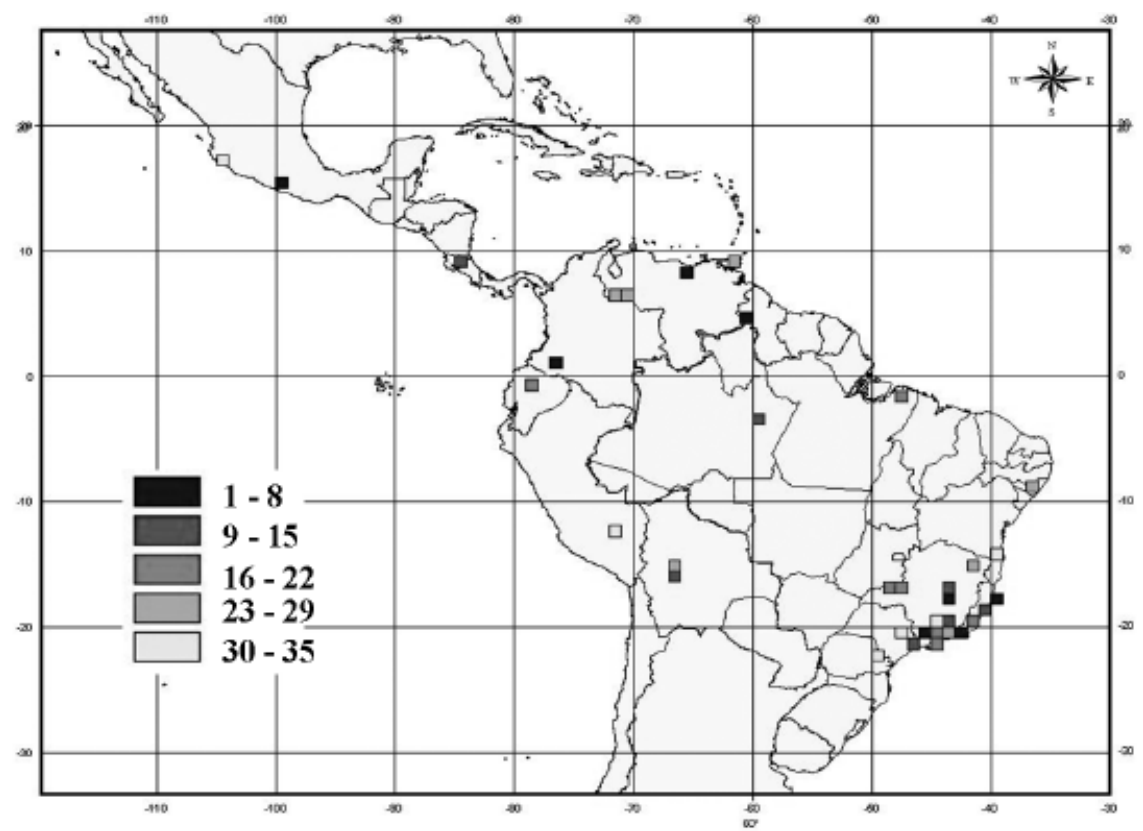

FIGURE 3. The minimum set of areas for the conservation of all Neotropical Bulbophyllum species included in the data set according to Complementarity analysis. The values represent an order of importance between the areas.

As expected, four of eight grids coincide with areas of high species richness identified in fig. 1, which indicates that each of the high diversity areas has a distinct species composition. Some of these areas are located in previously proposed Hotspots for other plant and animal groups in the American continent (Meyers et al. 2000).

\section{Conclusion}

One of the central theoretical tasks of conservation biology is to prioritize places on the basis of their biodiversity value and to devise management strategies to conserve biodiversity in these places (Meyers et al. 2000). This study shows how some tools can be useful for the fast identification of priority areas. However, we have to be aware of some problems when we accomplish studies of this nature: 1 . underestimation of the richness, once we know there are very few collections in herbaria; 2. use of only herbarium material (data of literature and personal communications are very useful information, but uncertain and non reproductible); 3. there is not a consensus about which estimator should be used and sometimes the results among them are conflicting and; 4 - the most important: we do not know if the collected places are still preserved.

For those reasons, a program for conservation in situ based exclusively in this type of data set could be a critical point and need to be observed in future political decisions concerning protected areas. We can exemplify practical situation based on field observation during this investigation:

1. Well collected places but actually strongly disturbed such as inland forests in Jaguariaíva, Paraná State, a historical site for plant collections. This was an important area in the complementarity analysis with several taxa and some endemic species in a grid cell. Nowadays the advance of Pinus forests for wood exploration seems to have been causing strong disturbance on original vegetation, bringing a large number of species to become seriously vulnerable.

2. Rare and endemics species. There are lots of species considered rare, but this is due to lack of knowledge. For example, an outcropping rock mountain area in Bahia State, known as Chapada Diamantina was recently investigated about Bulbophyllum occurrence (Ribeiro et al. 2005), increasing the number of species from five to twelve in two years of study. 
In this sense, another topic that should be pointed is the importance of distinguishing the regional definition (endemism) from areal definition (range restriction), (Peterson \& Watson 1998). Bulbophyllum manarae Foldats is an example of species described for Venezuela and is recently found in Northeast Brazil. In richness analyses of Brazilian species it might be considered endemic of an area as well as for analyses for Venezuela. Considering the whole of the Neotropical range it will be a widely distributed species showing the relationship among the mountains chain of Southeast Brazil and the Andean mountains.

The occurrence and richness patterns described here for the Bulbophyllum records were very similar to those for other organisms (e.g. butterflies, Brown 1987) and was described for many plant groups before (e.g. Prance 1987, Giulietti \& Pirani 1988, Knapp 2002), but it is still little explored and discussed in Orchidaceae.

To understand the diversity patterns of the orchid family in the Neotropical region is necessary to carry out investigations with similar approach exploring different taxa. Once the orchids are clearly a monophyletic family, the study of groups with different biological and ecological features, such as preference of habit and habitats, dispersive potential and pollination strategies could bring new insights about the diversification of orchid family in the American Continent.

Acknowledgments. We thank to American Orchid Society and FAPESB for financing the first author's study, to the Pos-Graduate Program in Botany of the Feira de Santana State University (UEFS), to National Council of Scientific and Technological development $(\mathrm{CNPq})$ and to Douglas C. Daly (NYBG) for consenting the use of Americas Base Map.

\section{Literature CITED}

Brown, K.S. 1987. Biogeography and evolution of Neotropical butterflies. In: Withmore, T.C. and Prance, G.T. Biogeography and Quaternary history in tropical America. Clarendon Press. Oxford. p. 66-99.

Colwell, R.K. \& J.A. Coddington. 1994. Estimating terrestrial biodiversity through extrapolation. Philos. Trans. R. Soc. Lond. B. 345: 101-118.
ESRI. 1999. ArcView ${ }^{\circledR G I S} 3.2 a$. Environmental Systems Research Institute, Inc. New York.

Felsenstein, J. 1985. Confidence limits on phylogenies: an approach using the bootstrap. Evol. 39: 783-791.

Garcia-Barros, E., P. Gurrea, M.J. Lucianez, J.M. Cano, M.L. Munguira, J.C. Moreno, H. Sainz, M.J. Sanz \& J.C. Simón. 2002. Parsimony analysis of endemicity and its application to animal and plant geographical distributions in the Ibero-Balearic region (western Mediterranean). J. Biogeogr. 29: 109-124.

Gentry, A.H. 1982. Neotropical floristic diversity: phytogeographical connections between Central and South America, Pleistocene climatic flutuations, or an accient of the Andean orogeny? Ann. Missouri Bot. Gard. 69 (3): 557-593.

Giulietti, A.M. \& J.R. Pirani. 1988. Patterns of geographic distribution of some plant species from Espinhaço range, Minas Gerais and Bahia, Brazil. In: P.E. Vanzolini\& W.R. Heyer (eds.). Proceedings of a workshop on Neotropical distribution patterns. Academia Brasileira de Ciências, Rio de Janeiro.

Gotelli, N.J. \& R.K. Colwell. 2001. Quantifying biodiversity: procedures and pitfalls in the measurement and comparison of species richness. Ecol. Letters 4: 379-391.

Hellmann, J.J. \& G.W. Fowler. 1999. Bias, precision, and accuracy of four measures of species richness. Ecol. Applic. 993: 824-834.

Hijmans, R.J., L. Guarino, M. Cruz \& E. Rojas. 2000. Computers tools for spatial analysis of plant genetic resources data: 1. DIVA-GIS. Plant Genet. Res. Newsl. 127: 15-19.

Hijmans, R.J., M. Cruz, E. Rojas \& L. Guarino. 2001. DIVA-GIS, Version 1.4. A geographic information system for the management and analysis of genetic resources data. Manual. International Potato Center, (CIP), Lima, Peru. http://www.cipotato.org/gis/; verified 5 October 2006;

Jarvis, A., M.E. Ferguson,D.E. Williams, L. Guarino, P.G. Jones, H.T. Stalker, J.F.M. Valls, R.N. Pittman, C.E. Simpson \& P. Bramel. 2002. Biogeography of wild Arachis: assessing conservation status and setting future priorities. Crop Sc. 43(3): 1100-1108.

Knapp, S. 2002. Assessing patterns of plant endemism in Neotropical uplands. Botan. Rev. 68 (1): 22-37.

Luer, C.A. 1972. The native orchids of Florida. The New York Botanical Garden. W.S. Cowell Ltd, Butter Market, Ipswich, England.

Magurran, A.E., 1988. Ecological diversity and its measurement. Princeton University Press, Princeton, U.S.A.

Meier, R. \& T. Dikow. 2004. Significance of specimen dataset from taxonomic revision for estimating and mapping the global species diversity of invertebrates and repatring reliable specimen data. Conserv. Biol. 18 (2): 478-488. 
Meyers, N., R.A. Mittermeier, C.G. Mittemeier, G.A.B Fonseca \& J. Kent. 2000. Biodiversity hotspots for conservation priorities. Nature 403: 863-858.

Page, R.D.M. 2001. NEXUS data editor, v. 0.5.0. (http://taxonomy.zoology.gla.ac.uk/rod/NDE/nde.html Accessed September 2006)

Peterson, A.T. \& D.M. Watson. 1998. Problems with areal definitions of endemism: the effects of spatial scaling. Diversity and Distributions 4: 189-194.

Prance, G.T. 1987. Biogeography of Neotropical plants. In: Withmore, T.C. and Prance, G.T. Biogeography and Quaternary history in tropical America. Clarendon Press. Oxford. p.46-65.

Rebelo, A.G. 1994. Iterative selection procedures: Centers of endemism and optimal placement of reserves. Strelitzia 1: 231-257.

Rebelo, A.G. \& W.R. Sigfried. 1992. Where should nature reserves be located in the Cape Floristic Region, South Africa? Models for the spatial configuration of a reserve network aimed at maximizing the protection of diversity. Conserv. Biol. 6: 243-252.
Ribeiro, P.L., E.L. Borba \& A.L.V. Toscano-de-Brito, 2005. O gênero Bulbophyllum Thouars (Orchidaceae) na Chapada Diamantina, Bahia, Brasil. Rev. Bras. Bot. 28 (3): 423-439.

Rosen, B.R. \& A.B. Smith. 1988. Tectonics from fossils? Analysis of reef-coral and sea-urchin distributions from late Cretaceous to Recent, using a new method. In: M.G. Audley-Charles \& A. Hallman (eds.). Gondwana and Tethys. Special Publication of the Geological Society of London 37: 275-306.

Swofford, D.L. 2000. PAUP: Phylogenetic analysis using parcimony and others methods, version 4.10. Sunderland: Sinquer.

Trejjo-Torres, J.C. \& J.D. Ackerman. 2001. Biogeography of the Antilles based on a parsimony analysis of orchid distributions. J.Biogeogr. 28: 775-794.

Walther, B.A., Morand, S. 1998. Compare performance of species richness estimation methods. Parasitilogy 116: 395-405.

Vermeulen, J.J. 1991. Orchids of Borneo vol. 2 Bulbophyllum. Toihaan Publishing Company. Sabah. Malaysia. 342p.

Eric Smidt initiated his studies in Orchidaceae in 1996, during his undergraduation, working in several orchid projects, such as "Phanerogamic flora of São Paulo State - Orchidaceae", and "The Orchidaceae of the Anchieta Island State Reserve", a rain forest park. His MSc. Degree in Botany was entitled "The subtribe Spiranthinae in the Chapada Diamantina, Bahia, Brazil". Since then, he has been involved with some projects regarding reproductive biology, genetics and conservation of Brazilian orchids. At the moment, he is doing his $\mathrm{PhD}$ thesis at Feira de Santana State University, Bahia, Brazil, working with "Taxonomic revision and phylogeny of Neotropical species of Bulbophyllum" under supervision of Dr. Eduardo L. Borba and Dr. Cássio van den Berg.

Viviane Silva-Pereira is graduated in Biology at Universidade Estadual Paulista, Brazil, has a master degree in Botany at Universidade Estadual de Feira de Santana, Brazil. Currently she is doing her $\mathrm{PhD}$ at the same University, with research focus on plant reproductive biology and plant population genetics associated with GIS framework.

Eduardo Leite Borba is graduated in Biology at Universidade Federal de Minas Gerais, Brazil, has a master degree and a PhD in Botany both at Universidade Estadual de Campinas, Brazil. Currently he is associate professor at Universidade Federal de Minas Gerais, Brazil, with research focus on orchid systematics, plant reproductive biology and plant population genetics.

Cassio van den Berg is graduated in Agriculture at Universidade de São Paulo, Brazil, has a master degree in Ecology at Universidade Estadual de Campinas, Brazil, and a PhD in Botany from the Royal Botanical Gardens, Kew and University of Reading, UK. Currently he is full professor at Universidade Estadual de Feira de Santana, Brazil, with research focus on orchid systematics, plant molecular systematics and plant population genetics. 